\title{
Physicochemical properties of various alginate-based raft-forming antacid products: a comparative study
}

\author{
Hemali M. Savla ${ }^{1}$, Isha V. Naik ${ }^{1}$, Chandrashekhar Gargote ${ }^{2}$, \\ Nischal Shashidhar ${ }^{3}$, Sneha Nair ${ }^{3}$, Mala D. Menon ${ }^{1 *}$
}

\author{
${ }^{1}$ Department of Pharmaceutics, IPA-MSB's Bombay College of Pharmacy, Mumbai, Maharashtra, India \\ ${ }^{2}$ Innovation and Development, Abbott Healthcare Pvt. Ltd., Mumbai, Maharashtra, India \\ ${ }^{3}$ Abbott India Ltd., Mumbai, Maharashtra, India
}

Received: 13 October 2021

Accepted: 29 October 2021

\section{*Correspondence:}

Dr. Mala D. Menon,

Email: maladmbcp@yahoo.co.in

Copyright: $($ ) the author(s), publisher and licensee Medip Academy. This is an open-access article distributed under the terms of the Creative Commons Attribution Non-Commercial License, which permits unrestricted non-commercial use, distribution, and reproduction in any medium, provided the original work is properly cited.

\begin{abstract}
Background: Alginate-based, raft-forming antacid products with reflux suppressant activity are complex formulations expected to achieve effective raft formation and cause elimination or displacement of the acid pocket, which is typically manifested in gastroesophageal reflux disease (GERD).

Methods: In the present study, six alginate-based raft-forming products commercially available in the Indian market were compared in terms of their acid neutralization properties, strength, resilience and structural and thermal properties of their rafts. Percent alginate content was also determined.

Results: Rafts of products containing calcium-based antacids formed voluminous, porous and floating rafts within seconds of addition to the simulated gastric fluid (SGF) compared with the products that contained aluminium and magnesium-based antacids. Marked differences were not evident in the ANC (acid neutralization capacity) values of the various products. No correlation was observed between ANC and raft-forming capacity or duration of neutralization. Raft structures affected their neutralization profiles. Rafts of porous and absorbent nature could retain their ANC probably due to release of trapped antacids. Further, raft strengths of only two products were above the British Pharmacopoeia specification of not less than $7.5 \mathrm{~g}$. Sodium alginate content was within specifications (85$115 \%$ ) for three of the six products.

Conclusions: Raft-forming formulations with higher alginate content and calcium-based antacids have better physicochemical properties such as ANC, neutralization profiles, raft strength and raft resilience than those with lower alginate content or those containing aluminium or magnesium-based antacids.
\end{abstract}

Keywords: Gastroesophageal reflux disease, Sodium alginate, Raft-forming formulations, Acid neutralization

\section{INTRODUCTION}

GERD is a chronic condition resulting from prolonged exposure of the esophagus to reflux from the stomach. ${ }^{1}$ It causes irritation of the esophageal lining, resulting in typical symptoms such as taste of acid in the back of the mouth, heartburn, bad breath, chest pain, regurgitation, breathing problems and teeth wear. Patients with GERD often have hiatal hernia, which places the acid pocket above the diaphragm, as a result of which the protective effect of the diaphragm against the reflux is lost, causing more frequent refluxes. ${ }^{2}$

Global prevalence of GERD was found to increase by $67.8 \%$ from 424 million cases in 1990 to 709 million cases in 2017 and distribution is reported to be around $17.1 \%$ in Europe, $18-27.7 \%$ in the US, $15 \%$ in the Middle Eastern countries, $14.1 \%$ in Australia, $10 \%$ in Asia and 
$2 \%$ in Africa. ${ }^{3,4}$ The overall prevalence in India is $~ 10 \%$, including both the rural and urban populations. ${ }^{5}$

Raft-forming formulations that are commonly used for the management of GERD act via a mechanism different from that of traditional antacids. They prevent the reflux of the acidic stomach contents into the esophagus by forming a viscous, gelatinous mass, which acts as a physical barrier between the gastric fluid and the esophageal mucosal lining. Some studies indicated that raft formation was able to effectively eliminate acid pockets in the postprandial state..$^{6-9}$

Alginic acid-based raft-forming agents have been available in the market for about 5 decades. These formulations were mainly composed of alginate and a bicarbonate salt. In the presence of gastric acid, the alginate precipitates to form an insoluble alginic acid gel, while the bicarbonate salt gets converted to carbon dioxide. This carbon dioxide gets entrapped within the alginate gel matrix, giving it the buoyancy to float over the gastric contents, thus forming a raft. ${ }^{1,10,11}$

Minor differences in the properties of alginate, its concentration and the type of antacid in the raft-forming formulations may affect the strength and properties of the raft formed. ${ }^{8,12,13}$ Antacids like calcium carbonate are reported to form rafts of greater strength and porosity compared with aluminum or magnesium-based antacids. ${ }^{6,14,15}$ Presence of sodium bicarbonate assists in producing effervescence, which gets entrapped in the gelatinous matrix of raft, making it light and buoyant; this helps the raft to remain floating and enhances the prevention of acid reflux. Thus, the performance of alginate-based raft-forming products with respect to raft formation and raft properties may be variable and will reflect in their in vivo performance. Thus, determination of the physical and chemical properties of the raft becomes important for assessment of product performance. ${ }^{8,11-14}$

The aim of this study was to evaluate the relevant physicochemical characteristics of six alginate-based raft formulations marketed in India as indicators of their in vivo raft performance.

\section{METHODS}

\section{Materials}

Six raft-forming products of different brands (Digeraft ${ }^{\mathrm{TM}}$, and five other commercial products RG, RR, RV, RT and $\mathrm{RM})$ were evaluated in this study. These products were similar in terms of the content of the active ingredients but had varying alginate:antacid ratios and antacid types. Digeraft $^{\mathrm{TM}}$ and RG contain calcium-based antacids. RR, RV, RT and RM contain aluminum and magnesiumbased antacids. Sodium alginate content per maximum dose was $1000 \mathrm{mg}$ for Digeraft ${ }^{\mathrm{TM}}$ and RG, $200 \mathrm{mg}$ for $\mathrm{RV}$ and RT and $100 \mathrm{mg}$ for RR and RM. Digeraft ${ }^{\mathrm{TM}}$ (manufactured by Naxpar Pharma Pvt. Ltd. and marketed by Abbott India Ltd.) was obtained from Abbott India Ltd. The other five products were obtained from local medical stores. Acetonitrile and disodium hydrogen orthophosphate were of high performance liquid chromatography (HPLC) grade (Qualigens Co., India). All other reagents were of analytical grade.

\section{Preliminary screening of raft testing conditions}

The maximum recommended dose (as mentioned on label) of raft-forming products was added to SGF. ${ }^{6}$ Based on preliminary trials, the testing conditions found to be optimum for further physicochemical characterization were (a) addition of formulation with a syringe as per British Pharmacopeia (BP); (b) SGF volume of $150 \mathrm{ml}$ and (c) vacuum filtration for washing of rafts of Digeraft $^{\mathrm{TM}}$, RG, RR, and $\mathrm{RM}$ and centrifugation for products RV and RT. ${ }^{6,16-19}$

\section{Neutralization studies}

Rafts were formed in SGF $\left(150 \mathrm{ml}\right.$, equilibrated to $37^{\circ} \mathrm{C}$ in a water bath for 20 mins), by adding the maximum recommended dose of the product using a syringe. The formed rafts were allowed to mature in a water bath $\left(37^{\circ} \mathrm{C}\right.$ for $30 \mathrm{mins}$ ) and used to assess the following neutralization parameters: $:^{6,20}$

\section{$A N C$}

After maturation, the rafts were given a series of washings: thrice with $40 \mathrm{ml}$ of deionized water by vacuum filtration/centrifugation, thrice with $40 \mathrm{ml}$ of chilled deionized water $\left(4^{\circ} \mathrm{C}\right)$ and twice with $40 \mathrm{ml}$ of chilled ethanol $\left(4^{\circ} \mathrm{C}\right)$; oven-dried to a constant weight at $40^{\circ} \mathrm{C}$ and then ground to a fine powder using mortar pestle. The powder was weighed and added to $70 \mathrm{ml}$ of deionized water $\left(37^{\circ} \mathrm{C}\right)$ and placed on a shaker water bath $\left(37^{\circ} \mathrm{C}\right.$ and $100 \mathrm{rpm}$ for $1 \mathrm{~min}$ ). To this mixture, $30 \mathrm{ml}$ of $1 \mathrm{M} \mathrm{HCl}\left(37^{\circ} \mathrm{C}\right)$ was added and maintained on the shaker bath under same conditions for 15 mins. The contents were then titrated with $0.5 \mathrm{M} \mathrm{NaOH}\left(37^{\circ} \mathrm{C}\right)$ at a constant increment of $0.7 \mathrm{ml}$ until the endpoint of $\mathrm{pH} 3.5$ was reached, $\mathrm{pH}$ being monitored using a calibrated $\mathrm{pH}$ meter. ${ }^{6}$

The ANC of the raft was calculated using the following formula,

$\mathrm{ANC}=\frac{[V(m l)-T(\mathrm{ml})] \times 0.5 \times \text { total mass of raft }(\mathrm{mg})}{\text { sample weight }(\mathrm{mg})}$,

where,

$\mathrm{V}=$ volume of $\mathrm{HCl}$ added to the sample,

$\mathrm{T}=$ volume of titer consumed by the sample,

raft mass=weight of dried raft, 
sample weight=weight of powder obtained after crushing the raft.

\section{Neutralization profile}

After discarding the SGF, developed and matured rafts were transferred to a Buchner funnel and mild vacuum filtration was applied to remove any excess SGF. Thereafter, $3 \mathrm{ml}$ of $0.04 \mathrm{M} \mathrm{HCl}$ ( $\mathrm{pH} 1.4$ ) was applied on the raft and allowed to settle for $5 \mathrm{~min} ; \mathrm{HCl}$ was removed using mild vacuum filtration over $3 \mathrm{~min}$, thereby completing a cycle of 8 mins. The $\mathrm{pH}$ of the filtrate was recorded. This was repeated consecutively until the $\mathrm{pH}$ of the filtrate was no longer neutralized by the raft $(\mathrm{pH}<4$ or $\mathrm{pH} \leq$ the previous reading). ${ }^{6,20}$ These rafts were used for studying the effect of raft structure.

\section{Effect of raft structure on neutralization profile}

The rafts, after completion of the neutralization profile study, were transferred into a $100 \mathrm{ml}$ beaker and broken using a spatula and $3 \mathrm{ml}$ of $0.04 \mathrm{M} \mathrm{HCl}$ was added. The mixture was allowed to settle and then transferred back to a Buchner funnel and filtered via mild vacuum filtration. The $\mathrm{pH}$ of the filtrate was recorded. Further, pattern of the acid flow, that is, through or from the sides of the raft and the speed of filtration were observed to assess the raft structure and its effect on acid neutralization. ${ }^{6}$

\section{Raft strength}

Raft strength was estimated using the modified balance method. ${ }^{21}$ Briefly, rafts were allowed to develop and mature around an L-shaped wire probe (diameter $=1 \mathrm{~mm}$; length of vertical arm $=9 \mathrm{~cm}$ and length of horizontal arm=2 cm) in $250 \mathrm{ml}$ glass beakers, while holding the wire probe upright in the central axis of the beaker throughout the maturation period. The beaker along with the raft on the wire probe was then carefully attached to one scale of the modified pan balance. Water was added dropwise on the other scale of the balance and the weight of water required to break the raft was recorded as raft strength. $^{22}$

\section{Raft resilience}

Rafts were prepared and allowed to mature as mentioned under neutralization studies. The medium was discarded and fresh SGF was added. Beakers were covered with aluminium foil and placed in a shaker bath $\left(37^{\circ} \mathrm{C}\right.$ and 50 rpm). At hourly intervals, rafts were examined for integrity, number of pieces, and time required for rafts to disappear. ${ }^{14,18,23}$

\section{Sodium alginate content}

Sodium alginate content was assessed by a validated HPLC method. The chromatographic system consisted of Agilent 1100 series with quaternary pump, column oven, photodiode array detector and autosampler. HPLC separations were performed on a stainless-steel Inertsil C18 analytical column $(250 \mathrm{~mm} \times 4.6 \mathrm{~mm})$ packed with 5 $\mu \mathrm{m}$ diameter particles. Data acquisition and analysis were carried out using Chemstation software version B.03.01(317).

Mobile phase A was acetonitrile and mobile phase B consisted of $50 \mathrm{mM}$ of disodium hydrogen orthophosphate buffer ( $\mathrm{pH}$ 6.0). Gradient elution was carried out: $100 \%$ mobile phase B was first held at 0.5 $\mathrm{ml} / \mathrm{min}$ for $5 \mathrm{~min}$, then mobile phase A was raised up to $50 \%$ at $1 \mathrm{ml} / \mathrm{min}$ in $6 \mathrm{~min}$ and held at this level at 1 $\mathrm{ml} / \mathrm{min}$ until $15 \mathrm{~min}$; at $16 \mathrm{~min}$, mobile phase $\mathrm{B}$ was switched back to $100 \%$ at $0.5 \mathrm{ml} / \mathrm{min}$ until $25 \mathrm{~min}$ (reequilibration). The injection volume was $50 \mu \mathrm{l}$ and the column temperature was maintained at $40^{\circ} \mathrm{C}$. The detection wavelength was set at $205 \mathrm{~nm}$.

A 6-point linearity plot of concentration versus area was constructed by analyzing a series of concentrations of sodium alginate standard by HPLC as per the abovementioned chromatographic conditions.

\section{Assay procedure}

The assay was performed in triplicate as described previously with minor modifications. ${ }^{24}$ Briefly, $5 \mathrm{ml}$ of the raft-forming suspension was dispersed in $200 \mathrm{ml}$ of mobile phase B in a $250 \mathrm{ml}$ volumetric flask and sonicated for $30 \mathrm{~min}$, with intermittent shaking. The dispersion was allowed to cool, volume was made up to $250 \mathrm{ml}$ with mobile phase $\mathrm{B}$, followed by centrifugation at $4000 \mathrm{rpm}$ for $5 \mathrm{~min}$. The supernatant was diluted with mobile phase B and filtered using a $0.45 \mu \mathrm{m}$ syringe filter, discarding the first $2 \mathrm{ml}$ of filtrate. The samples were analyzed by the above validated HPLC method. The sodium alginate concentration in each sample was determined using the linear equation and the percent assay of sodium alginate for each product was calculated using the following equation,

$\%$ assay of sodium alginate

$=\frac{X(\mathrm{mg} / \mathrm{ml}) \times 250 \mathrm{ml} \times \text { dilution factor } \times 100}{L C}$,

where, $X(\mathrm{mg} / \mathrm{ml})=$ sodium alginate concentration in each sample, LC=label claim ( $\mathrm{mg}$ of sodium alginate per $5 \mathrm{ml}$ of suspension).

The percent sodium alginate in each product was expected to be in the range of $84.0-116.0 \%$ of the labelled amount of sodium alginate. ${ }^{16}$

\section{Structural analysis by Fourier transform infrared spectroscopy (FT-IR)}

The FT-IR spectra of the prepared discs of the powdered raft samples and standard alginate sample were recorded using Jasco FT/IR-4100 type A instrument. ${ }^{6}$ 


\section{Thermal analysis by differential scanning calorimetry (DSC)}

DSC measurements of the raft samples as well as the standard alginate sample were made using a Mettler Toledo DSC1 STARe. A sample mass of $\sim 7 \mathrm{mg}$ in a covered aluminium sample holder with a central pin hole was subjected to heating from $25^{\circ} \mathrm{C}$ to $350^{\circ} \mathrm{C}$ at a rate of $5^{\circ} \mathrm{C} / \mathrm{min}$, The thermograms were recorded and processed using the STARe software. ${ }^{6}$

\section{Statistical methods}

Data reported are representative of three independent experiments for each parameter. Statistical analyses were performed using GraphPad Prism 8 (GraphPad Software, La Jolla, CA). ANC data, neutralization time, raft strength and alginate content within the raft of the reference product and other marketed products were analyzed using one-way analysis of variance (ANOVA) with $\mathrm{p}<0.05$ considered as statistically significant. Multiple comparisons were made post-hoc using Bonferroni test, with corrected $\mathrm{p}<0.01$ considered as statistically significant.

\section{RESULTS}

\section{Acid neutralization properties of various raft formulations}

The ANCs of rafts of each of the six products were compared for speed of raft formation, nature of the raft formed as well as their ability to retain a reservoir of antacid within their structures, and thereby provide benefit in controlling acid reflux. ANC values and raftforming characteristics of various raft formulations are presented in Table 1.

ANC of RR was the highest and it was significantly higher $(\mathrm{p}<0.05)$ than that of products RV, RT and RM. Digeraft $^{\mathrm{TM}}, \mathrm{RG}$ and $\mathrm{RR}$ were not significantly different from each other in terms of ANC and they formed better rafts compared to RV and RT (Table 1).
Digeraft $^{\mathrm{TM}}$, $\mathrm{RG}$ and $\mathrm{RM}$ formed buoyant rafts within seconds of addition of the suspension to SGF and floated on the surface of the medium. The speed of raft formation for these products was considered as immediate and their floatation as complete.

The other three products required 8-10 mins to form rafts and hence their formation speed was considered to be slow. In case of products RR and RT, some material floated on the surface of SGF while remaining amount sank to the bottom of the beaker throughout the maturation period. The floatation was considered as partial for these two products. For product RV, the insoluble material remained at the bottom of the beaker throughout the $30 \mathrm{~min}$ raft maturation time and was assessed to have very low floatation.

Rafts of Digeraft ${ }^{\mathrm{TM}}$ and $\mathrm{RG}$ remained substantially intact when removed from the beaker. The rafts of RR and RM broke into fewer particles, and those of RV and RT broke into numerous small particles. Thus, raft coherence was considered to be good for Digeraft ${ }^{\mathrm{TM}}$ and $\mathrm{RG}$, average for $\mathrm{RR}$ and RM and poor for RV and RT.

Based on their antacid content, ANC and raft characteristics, the six raft-forming products were classified into three groups as products with average coherence (high ANC and no calcium ion source [RR]); products with good coherence (high ANC and a calcium ion source [Digeraft ${ }^{\mathrm{TM}}$ and $\mathrm{RG}$ ]); and products average to poor coherence (low ANC and no calcium source [RV, $\mathrm{RT}$, and RM]).

Thus, high ANC, coupled with the presence of calcium ions as cross-linker, could be important factors for obtaining coherent rafts as inferred by Hampson et al. ${ }^{14}$

Acid passing through the rafts was assessed over consecutive reflux events of 8 mins each, to study the potential acid neutralization benefit of the antacid trapped within the rafts. Figure 1 shows the time course of neutralization for each product.

Table 1: ANC and raft forming characteristics of various raft formulations.

\begin{tabular}{|lllll|}
\hline Product codes & ANC mean $($ SD $)$ & Formation speed & Floatation & Coherence \\
\hline Digeraft & $16.5(1.42)$ & Immediate & Complete & Good \\
\hline RG & $17.2(1.97)$ & Immediate & Complete & Good \\
\hline RR & $19.7(2.14)^{*+\#}$ & Slow & Partial & Average \\
\hline RV & $15.2(0.13)^{*}$ & Slow & Very low & Poor \\
\hline RT & $15.0(0.02)^{+}$ & Slow & Partial & Poor \\
\hline RM & $15.2(0.91)^{\#}$ & Immediate & Complete & Average \\
\hline
\end{tabular}

Data represent a mean of three independent experiments; ANC, acid neutralization capacity; SD, standard deviation; *ANC of products RR and RV are significantly different; ${ }^{+}$ANC of products RR and RT are significantly different; ${ }^{*}$ ANC of products RR and RM are significantly different. 


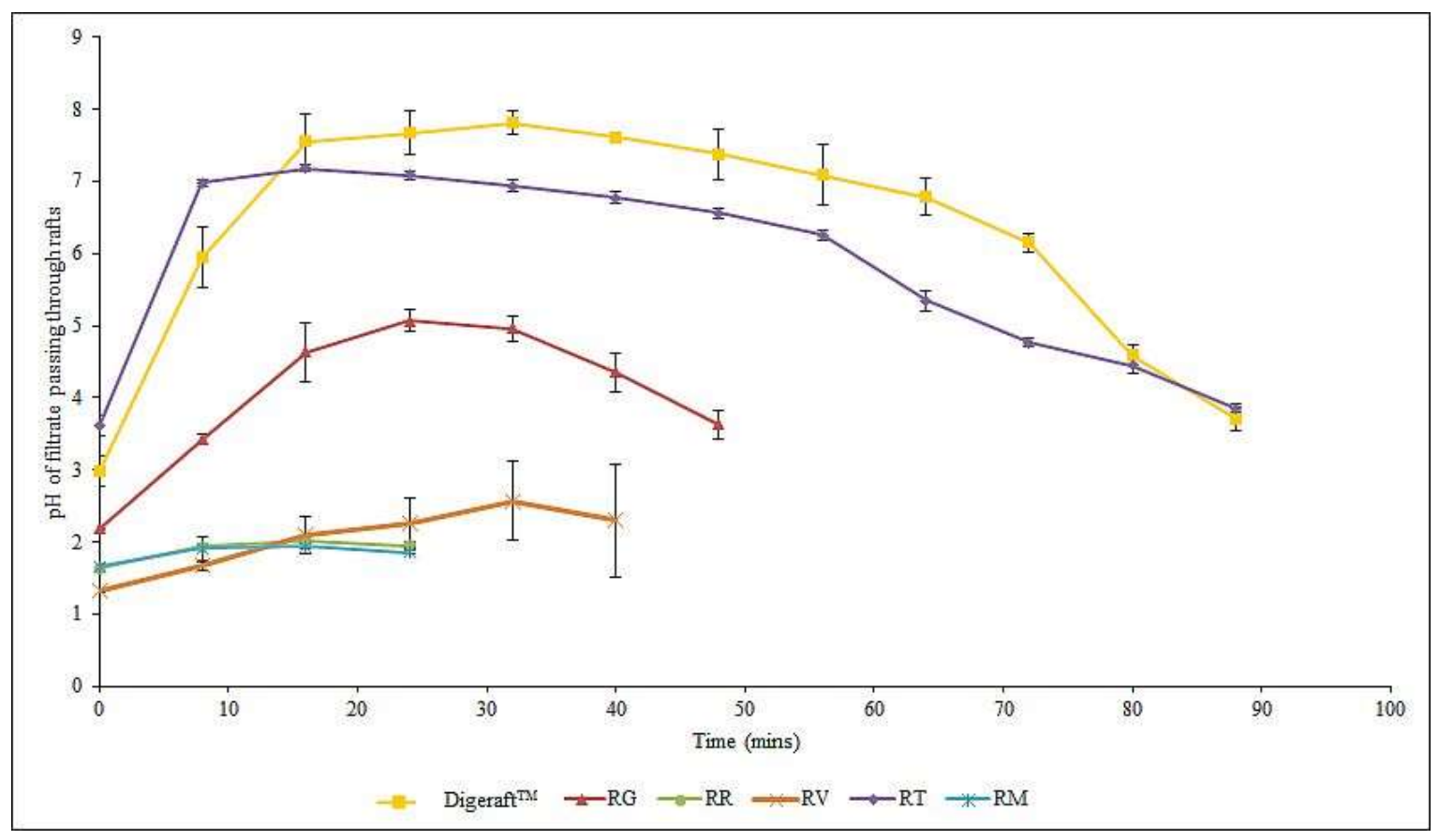

Figure 1: Neutralization profiles of rafts.

Matured rafts were treated with $0.04 \mathrm{M} \mathrm{HCl}$ for 5 mins, and the acid was removed by mild vacuum filtration over a period of 3 mins. The process was repeated until no further neutralization was observed. Data are represented as mean of 3 independent experiments.

Digeraft $^{\mathrm{TM}}$ and RT were the products with the longest duration of neutralization of $88 \mathrm{~min}$, which was significantly longer $(p<0.05)$ than that of other four products. In contrast, RR, which had the highest ANC was found to have shortest duration of neutralization of 21 mins, along with RM. RG and RV demonstrated intermediate duration of neutralization. No correlation could be established between the ANC and neutralization profiles of rafts.

Though the rafts of Digeraft ${ }^{\mathrm{TM}}, \mathrm{RG}$ and $\mathrm{RR}$ exhibited similar ANC values, neutralization duration was more prolonged for Digeraft ${ }^{\mathrm{TM}}$ and $\mathrm{RG}$ as compared with RR. The higher alginate content in Digeraft ${ }^{\mathrm{TM}}$ and $\mathrm{RG}$ can enhance antacid entrapment within the raft structure and subsequently prolong the duration of neutralization. In contrast, RR had lower alginate concentration; hence, its shorter duration of neutralization. Raft structures can substantially affect the duration of neutralization. Table 2 summarizes the duration of neutralization, pattern of acid filtration through the rafts and structure of the rafts.

The rafts of all the six products were able to neutralize $0.04 \mathrm{M} \mathrm{HCl}$ solution after they were broken, but to varying degrees. In case of Digeraft ${ }^{\mathrm{TM}}$ and $\mathrm{RG}$, the acid filtered through the whole raft during the filtration step, thereby suggesting a highly porous and absorbent raft structure. For products RR, RV and RT, the acid filtered through and from the sides of the raft, while for RM, the acid filtered completely from the sides of the raft, and the rate of filtration was very fast. Thus, the intermediate or non-existent porosity and absorbance capacity of these rafts could have shielded the acid and resulted in shorter duration of neutralization. These results indicated that absorbent rafts with optimum porosity can effectively neutralize the gastric acid and prolong the duration of neutralization as evident from the longest total duration of neutralization observed for Digeraft ${ }^{\mathrm{TM}}$ and $\mathrm{RG}$. The moderately porous rafts of RT also showed a longer total duration of neutralization and this duration was not significantly different than that of Digeraft ${ }^{\mathrm{TM}}$ and $\mathrm{RG}$. The other three products depicted significantly lower total durations of neutralization, which can be attributed to their lower or non-existent porosity and absorbance capacity.

Although no correlation could be established between ANC values and neutralization profiles of the rafts, there was a strong correlation between raft structure and neutralization profiles. Digeraft ${ }^{\mathrm{TM}}$ and $\mathrm{RG}$, which had absorbent and porous raft structures, exhibited a longer duration of neutralization, compared with RR, RV, and RM. This effect could be attributed to the calcium ions and higher alginate content in the formulations of Digeraft $^{\mathrm{TM}}$ and $\mathrm{RG}$ resulting in greater antacid trapping within rafts which, in turn, neutralized the gastric acid more efficiently. ${ }^{6} \mathrm{RR}, \mathrm{RV}$ and RT did not contain calcium carbonate, which could explain their non-absorbent raft structures and resultant inferior ANCs. ${ }^{18,23}$ In contrast, RM, which did not form porous and buoyant rafts, also yielded a good neutralization profile; however, no definite reason could be attributed to it. 
Table 2: Neutralization profile of various raft formulations.

\begin{tabular}{|c|c|c|c|c|c|}
\hline $\begin{array}{l}\text { Product } \\
\text { names }\end{array}$ & $\begin{array}{l}\text { Duration of } \\
\text { neutralization } \\
\text { after breaking } \\
\text { the raft (min) }\end{array}$ & $\begin{array}{l}\text { Total duration } \\
\text { of } \\
\text { neutralization } \\
(\mathrm{min})^{2}\end{array}$ & Passage of acid & $\begin{array}{l}\text { Speed of } \\
\text { filtration }\end{array}$ & Raft structure \\
\hline & Mean (SD) & Mean (SD) & & & \\
\hline Digeraft $^{\mathrm{TM}}$ & $53.3(4.62)$ & $144(8)$ & Through the raft & Slow & Porous, absorbent \\
\hline RG & $93.3(4.62)$ & $144(8)$ & Through the raft & Slow & Porous, absorbent \\
\hline $\mathbf{R R}$ & $18.7(4.62)$ & $40(8)$ & $\begin{array}{l}\text { Through and from the } \\
\text { sides of raft }\end{array}$ & Moderate & $\begin{array}{l}\text { Moderate porosity and } \\
\text { absorbent properties }\end{array}$ \\
\hline $\mathbf{R V}$ & $42.7(4.62)$ & $80(8)$ & $\begin{array}{l}\text { Through and from the } \\
\text { sides of raft }\end{array}$ & Moderate & $\begin{array}{l}\text { Moderate porosity and } \\
\text { absorbent properties }\end{array}$ \\
\hline RT & $32.0(8.00)$ & $120(16)$ & $\begin{array}{l}\text { Through and from the } \\
\text { sides of raft }\end{array}$ & Moderate & $\begin{array}{l}\text { Moderate porosity and } \\
\text { absorbent properties }\end{array}$ \\
\hline $\mathbf{R M}$ & $18.7(4.62)$ & $40(8)$ & From the sides of raft & $\begin{array}{l}\text { Fast and without } \\
\text { vacuum }\end{array}$ & $\begin{array}{l}\text { Low porosity and } \\
\text { absorbent properties }\end{array}$ \\
\hline
\end{tabular}

Table 3: Resilience of various rafts formulations.

\begin{tabular}{|ll|}
\hline $\begin{array}{l}\text { Product } \\
\text { names }\end{array}$ & $\begin{array}{l}\text { Observations } \\
\text { Digeraft }\end{array}$ \\
\hline TM & $\begin{array}{l}\text { Smaller pieces started breaking from the lower portion of the raft in } 4 \text { hours. Further disruption of the } \\
\text { lower portion and increase in the number of particles were observed up to 24 hours. However, a major } \\
\text { amount of raft remained intact after } 24 \text { hours }\end{array}$ \\
\hline RR & $\begin{array}{l}\text { Smaller pieces started breaking from the lower portion of the raft in } 2 \text { hours. Further disruption of the } \\
\text { lower portion and increase in the number of particles were observed up to } 24 \text { hours. However, a major } \\
\text { amount of raft remained intact after } 24 \text { hours }\end{array}$ \\
\hline RV & $\begin{array}{l}\text { Raft broke into numerous smaller pieces in } 2 \text { hours } \\
\text { Raft broke into numerous smaller pieces within } 1 \text { hour. These broken pieces started settling at the bottom } \\
\text { hours }\end{array}$ \\
\hline RT & $\begin{array}{l}\text { Raft broke into numerous smaller pieces in } 2 \text { hours. Further increase in the number of particles was } \\
\text { observed up to } 24 \text { hours. }\end{array}$ \\
\hline RM & $\begin{array}{l}\text { Raft broke into numerous smaller pieces in } 2 \text { hours. Porous structure was also lost in } 2 \text { hours and a } \\
\text { gelatinous mass remained floating. }\end{array}$ \\
\hline
\end{tabular}

Data reported are representative of three independent experiments.

Table 4: Summary of overall performance.

\begin{tabular}{|c|c|c|c|c|c|c|c|c|}
\hline \multirow{2}{*}{ Test parameters } & \multirow{2}{*}{$\begin{array}{l}\text { Product } \\
\text { Codes }\end{array}$} & \multicolumn{6}{|c|}{ Statistical difference between products } & \multirow{2}{*}{ Statistical summary } \\
\hline & & $\mathbf{A}$ & B & $\mathbf{C}$ & D & $\mathbf{E}$ & $\mathbf{F}$ & \\
\hline \multirow{6}{*}{$\mathrm{ANC}^{1}$} & Digeraft ${ }^{\mathrm{TM}}$ & & & & & & & \multirow{6}{*}{$\begin{array}{l}\text { ANC of product RR was } \\
\text { highest and significantly } \\
\text { greater than that of products } \\
\mathrm{RV}, \mathrm{RT} \text {, and RM; Digeraft } \\
\text { and RG were not significantly } \\
\text { different from remaining four } \\
\text { products. }\end{array}$} \\
\hline & RG & & & & & & & \\
\hline & RR & & & & $*$ & $*$ & $*$ & \\
\hline & $\mathrm{RV}$ & & & * & & & & \\
\hline & RT & & & $*$ & & & & \\
\hline & $\mathrm{RM}$ & & & * & & & & \\
\hline \multirow{6}{*}{$\begin{array}{l}\text { Total duration of } \\
\text { neutralization }\end{array}$} & Digeraft ${ }^{\mathrm{TM}}$ & & & $* * * *$ & $* * * *$ & & $* * * *$ & \multirow{6}{*}{$\begin{array}{l}\text { Digeraft }{ }^{\mathrm{TM}} \text { and RG exhibited } \\
\text { longest duration of } \\
\text { neutralization; Digeraft } \\
\text { RG, and RT were significantly } \\
\text { better than products RR, RV, } \\
\text { and RM; RV was significantly } \\
\text { better than RR and RM }\end{array}$} \\
\hline & RG & & & $* * * *$ & $* * * *$ & & $* * * *$ & \\
\hline & RR & $* * * *$ & $* * * *$ & & $* *$ & $* * * *$ & & \\
\hline & RV & $* * * *$ & $* * * *$ & $* *$ & & $* *$ & $* *$ & \\
\hline & RT & & & $* * * *$ & $* *$ & & $* * * *$ & \\
\hline & $\mathrm{RM}$ & $* * * *$ & $* * * *$ & & $* *$ & $* * * *$ & & \\
\hline
\end{tabular}




\begin{tabular}{|c|c|c|c|c|c|c|c|c|}
\hline Test parameters & Product & \multicolumn{6}{|c|}{ Statistical difference between products } & \multirow{7}{*}{$\begin{array}{l}\text { Statistical summary } \\
\text { Rafts of Digeraft }{ }^{\mathrm{TM}} \text { and } \mathrm{RG} \\
\text { were the strongest and } \\
\text { significantly better than other } \\
\text { four products; RR and RT } \\
\text { formed significantly stronger } \\
\text { rafts than RM, which was } \\
\text { significantly better than RV }\end{array}$} \\
\hline \multirow{6}{*}{ Raft strength ${ }^{3}$} & \multicolumn{3}{|l|}{ Digeraft ${ }^{\mathrm{TM}}$} & \multirow{3}{*}{$\begin{array}{l}* * * * \\
* * * *\end{array}$} & \multirow{3}{*}{$\begin{array}{l}* * * * \\
* * * *\end{array}$} & \multirow{2}{*}{$\begin{array}{l}* * * * \\
* * * *\end{array}$} & \multirow{2}{*}{$\begin{array}{l}* * * * \\
* * * *\end{array}$} & \\
\hline & RG & & & & & & & \\
\hline & RR & $* * * *$ & $* * * *$ & & & & & \\
\hline & RV & $* * * *$ & $* * * *$ & & & & $*$ & \\
\hline & RT & $* * * *$ & $* * * *$ & & & & & \\
\hline & $\mathrm{RM}$ & $* * * *$ & $* * * *$ & & $*$ & & & \\
\hline & Digeraft $^{\mathrm{TM}}$ & & $* *$ & $* * * *$ & $* * * *$ & & $* * * *$ & Digeraft $^{\mathrm{TM}}, \mathrm{RG}$, and $\mathrm{RT}$ \\
\hline & RG & $* *$ & & $* * * *$ & $* * * *$ & $* *$ & $* * * *$ & complied with the BP \\
\hline Alginate content & $\mathrm{RR}$ & $* * * *$ & $* * * *$ & & $* * * *$ & $* * * *$ & & specified range for label claim \\
\hline$(\% \text { label claim })^{4}$ & RV & $* * * *$ & $* * * *$ & $* * * *$ & & $* * * *$ & $* * * *$ & and were significantly \\
\hline & RT & & $* *$ & $* * * *$ & $* * * *$ & & $* * * *$ & superior to the outliers (RR, \\
\hline & $\mathrm{RM}$ & $* * * *$ & $* * * *$ & & $* * * *$ & $* * * *$ & & RV and RM). \\
\hline
\end{tabular}

${ }^{1} \mathrm{ANC}: * \mathrm{p}<0.05 ;{ }^{2}$ Total duration of neutralization: $* * \mathrm{p}<0.05 ; * * * * \mathrm{p}<0.0001 ;{ }^{3}$ Raft strength: $* \mathrm{p}<0.05 ; * * * \mathrm{p}<0.0001 ;{ }^{4}$ Alginate content (\% label claim): $* * \mathrm{p}<0.01 ; * * * \mathrm{p}<0.0001$; BP, British Pharmacopoeia.

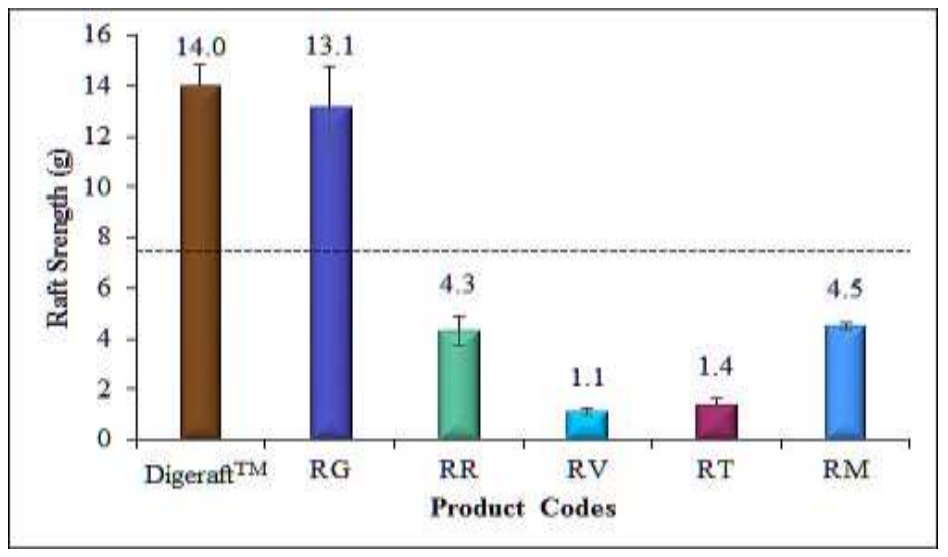

Figure 2: Raft strengths of various raft formulations.

Rafts were developed and allowed to mature around an L-shaped wire probe, which was attached to a modified pan balance. Water was added to the pan and the weight of water required to break the raft was recorded as raft strength. Data are represented as mean of 3 experiments. The dotted horizontal line represents the cut-off for the British Pharmacopoeia-specified acceptable range, i.e., 7.5g.

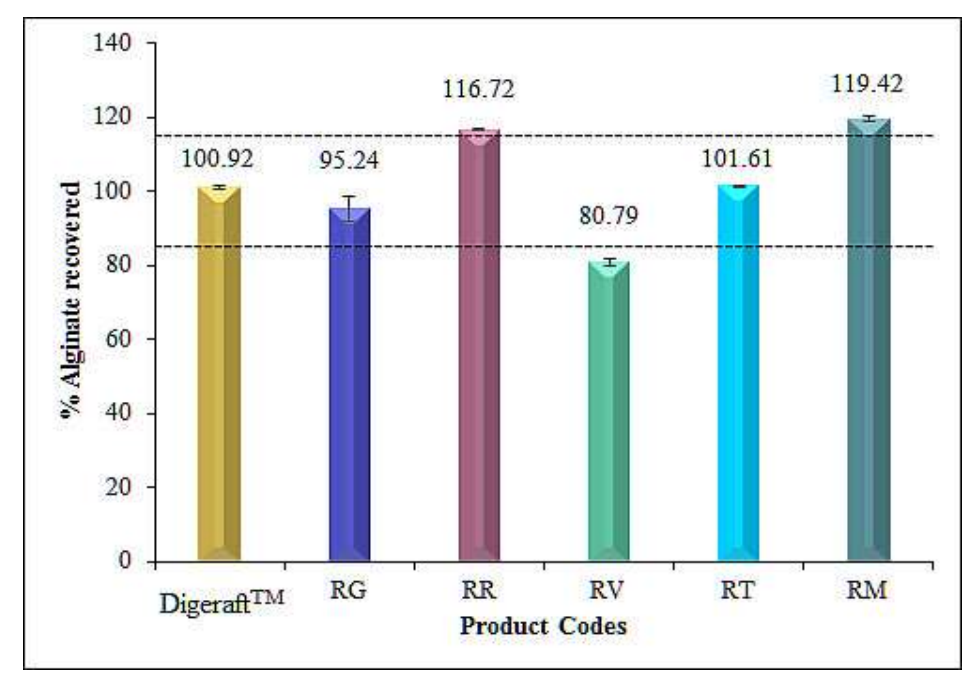

Figure 3: Sodium alginate content in various raft-forming products.

Alginate content in the raft-forming suspensions was assessed using HPLC method using Agilent 1100 series and C18 analytical column $(250 \mathrm{~mm} \mathrm{X} 4.6 \mathrm{~mm} \mathrm{X} 5 \mu$ ) and Chemstation software with gradient elution of acetonitrile and phosphate buffer pH 6 . Data are represented as a mean of 3 experiments. The dotted horizontal lines represent the cut-offs for the British Pharmacopoeia-specified acceptable range, i.e., $85 \%-115 \%$. 


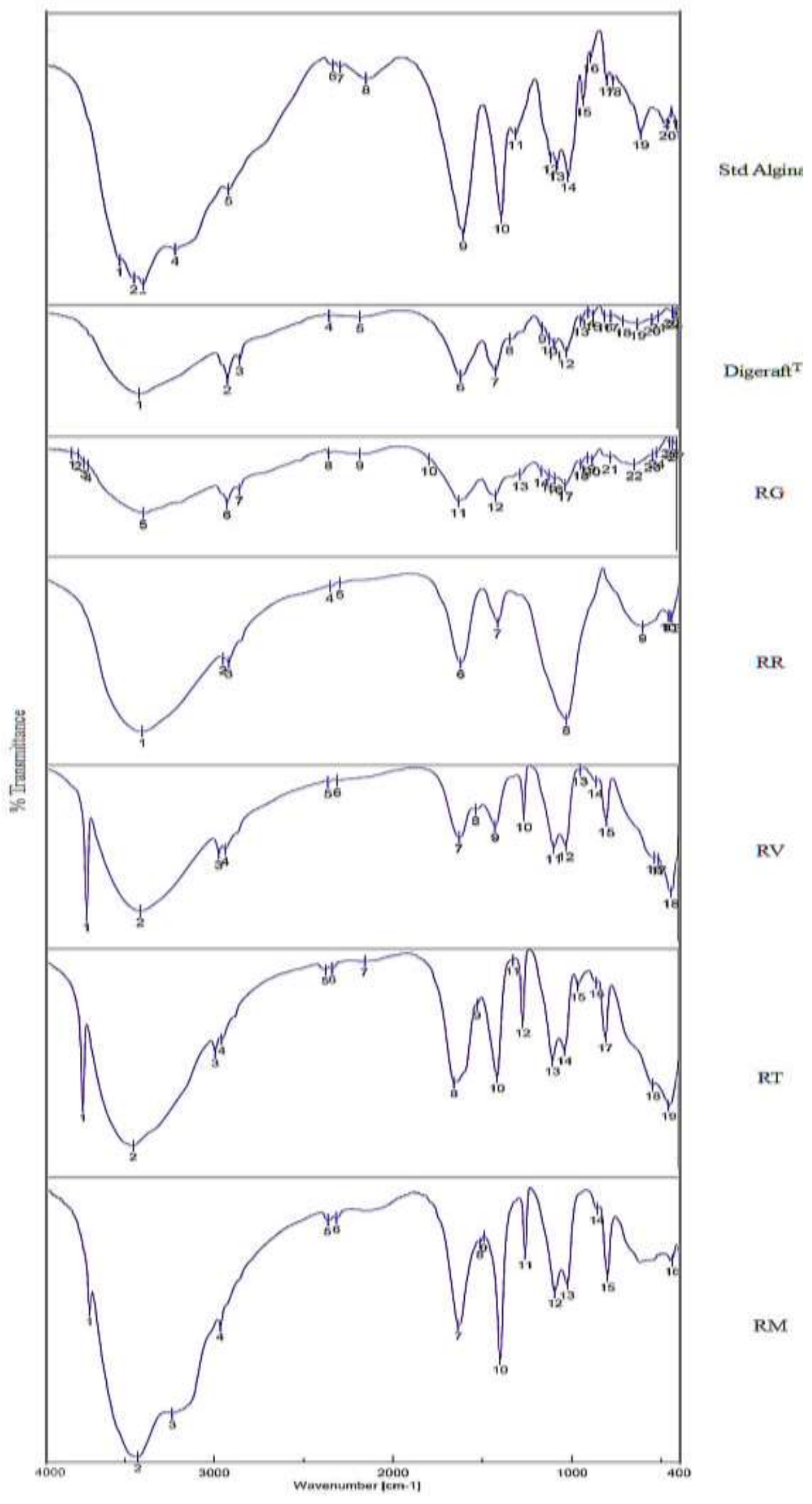

Figure 4: Fourier transform-infrared spectra of various raft formulations.

Spectra of powdered rafts mixed with potassium bromide were scanned and recorded using Jasco FT/IR-4100 type A instrument. (3211$3320 \mathrm{~cm}-1$ - stretching vibration of O-H bond, $1582-1649 \mathrm{~cm}-1$ and 1405-1426 cm-1 stretching vibrations of -COO- and 1155-1163, 1072-1083, 1010-1027, and 945-969 cm-1 - stretching of the $\mathrm{CO}$ and $\mathrm{OH}$ bonds) 


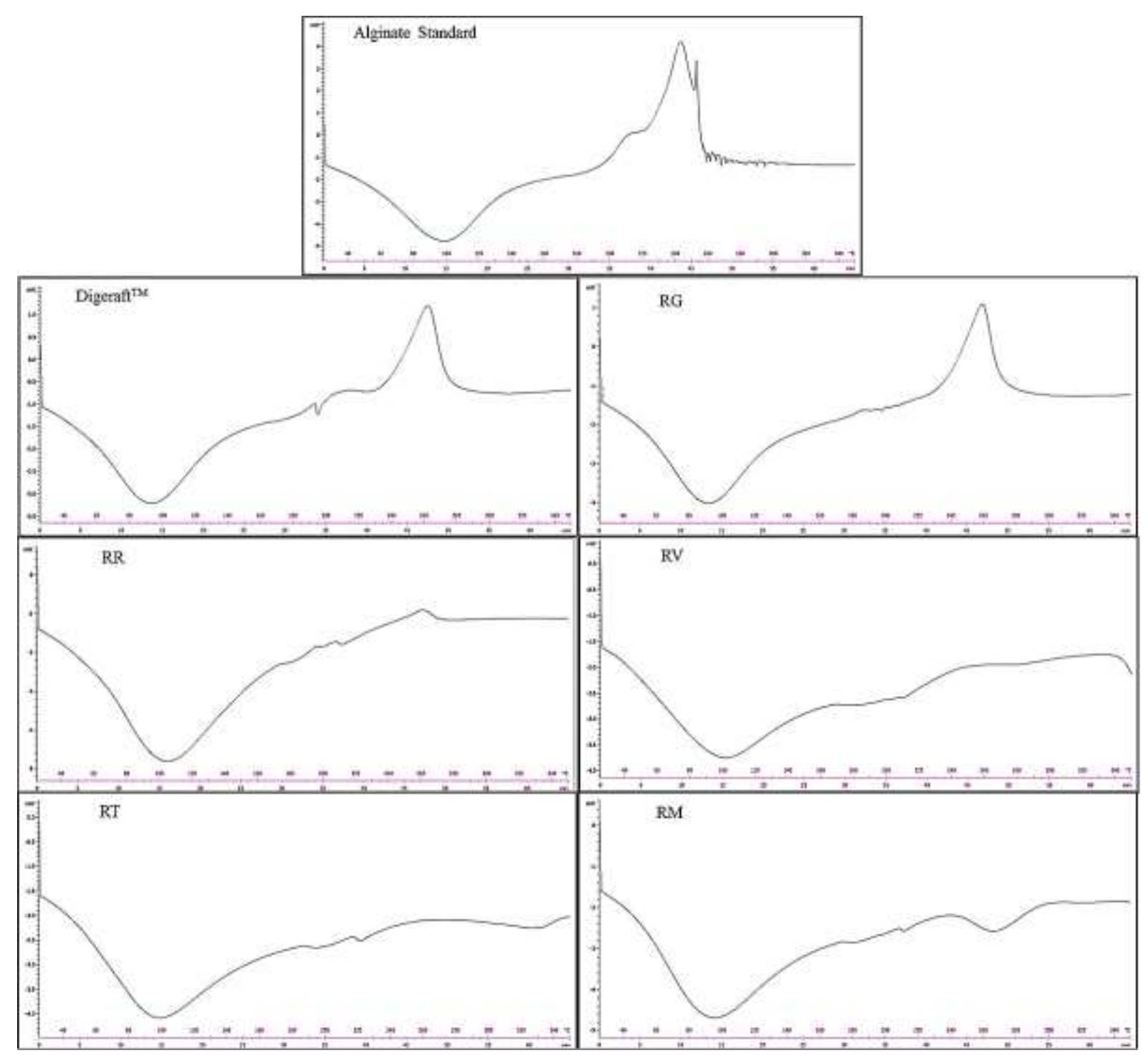

Figure 5: Thermograms of various raft formulations.

Legend to be added to the figure - DSC measurements were performed using Mettler Toledo DSC with Stare Software using $7 \mathrm{mg}$ raft sample at $5^{\circ} \mathrm{C} / \mathrm{min}$ from $25^{\circ} \mathrm{C}$ to $350^{\circ} \mathrm{C}$. (exothermic decomposition peaks in range of $220^{\circ} \mathrm{C}-300^{\circ} \mathrm{C}$ indicates the transition of alginate from amorphous to crystalline form) DSC, differential scanning calorimetry.

\section{Raft strength and resilience of various formulations}

The raft strengths for the six products at their maximum doses are shown in Figure 2.

Rafts of Digeraft ${ }^{\mathrm{TM}}$ and $\mathrm{RG}$ were strongest, equivalent in terms of raft strength values and complied with the BP specification (mean raft strength not less than $7.5 \mathrm{~g}$ ). ${ }^{16}$ The difference between the raft strengths of these two products and those of other four products was statistically significant $(\mathrm{p}<0.05)$.

The observations of the resilience study are summarized in Table 3.

Rafts of Digeraft ${ }^{\mathrm{TM}}$ retained their integrity longer (4 hours) than the other products and these rafts retained their porous and buoyant structure. The raft of product
RG started losing its integrity in 2 hours but retained its structure thereafter. For the other four products, the rafts broke into numerous smaller pieces within 1-2 hours. The raft pieces settled at the bottom of the beaker in case of products RR, RV and RT, while those of product RM floated as gelatinous mass.

The antacid components of the raft-forming products have a significant influence on the strength and resilience of the rafts. The calcium ions in Digeraft ${ }^{\mathrm{TM}}$ and $\mathrm{RG}$ could crosslink with alginate salts to form a typical eggbox structure and produced rafts of greater inherent strength and resilience. ${ }^{12} \mathrm{RR}, \mathrm{RV}$ and $\mathrm{RT}$, which contained aluminium-based antacids, exhibited poor raft strengths. RM, which did not contain either calcium carbonate or aluminium salts, also had poor raft strength, but slightly higher than that of aluminium-containing products. ${ }^{6,11,13}$ 


\author{
Sodium alginate content in various raft-forming \\ suspensions
}

The sodium alginate content was within specifications for Digeraft $^{\mathrm{TM}}, \mathrm{RG}$ and RT (Figure 3). The content was found to be $<85 \%$ for RV and $>115 \%$ for RR and RV. Sodium alginate content of Digeraft ${ }^{\mathrm{TM}}$ and RT was closest to the label claim and these products were significantly superior $(\mathrm{p}<0.05)$ to the remaining four.

\section{Structural aspects of various raft formulations}

Figure 4 shows the FT-IR spectra of the rafts of the six products, along with standard alginate sample. All the rafts displayed the characteristic bands as in the alginate standard. A broad band with minimum transmittance in the range of $3211-3320 \mathrm{~cm}-1$ that depicted stretching vibrations of the $\mathrm{O}-\mathrm{H}$ bond was observed in all the rafts. The asymmetric and symmetric stretching vibrations of COO- can be assigned to the peaks in the range of 1582$1649 \mathrm{~cm}^{-1}$ and $1405-1426 \mathrm{~cm}^{-1}$, respectively. Several alginate-specific absorbance bands can be seen at 11551163, 1072-1083, 1010-1027 and 945-969 $\mathrm{cm}^{-1}$, which can be attributed to stretching of the $\mathrm{CO}$ and $\mathrm{OH}$ bonds. ${ }^{6}$

\section{Thermal analysis of various raft formulations}

The DSC thermograms for each product are shown in Figure 5. The DSC thermograms of the standard alginate and the isolated rafts exhibited one or two exothermic decomposition peaks within the range of $220^{\circ} \mathrm{C}-300^{\circ} \mathrm{C}$, thereby corroborating the presence of the biopolymer in the raft-forming formulations and transition of alginate from amorphous to crystalline form. ${ }^{6}$

The variations in the decomposition temperature may be attributed to interaction of inorganic antacid compounds with the alginate. ${ }^{6}$ The higher carbonate content in Digeraft $^{\mathrm{TM}}$ and $\mathrm{RG}$ accounts for the bigger exothermic peaks observed for their rafts. For rafts of RV and RT, the decomposition peak was of lower resolution, probably due to their different antacid content.

\section{Overall performance of various raft formulations}

Table 4 summarizes the performance of the six products. For each parameter, the difference between the six products is represented in terms of statistical significance. Product RR had the highest ANC, but Digeraft ${ }^{\mathrm{TM}}, \mathrm{RG}$ and RT depicted longest duration of neutralization. The products also varied significantly in terms of the strength and resilience of their rafts.

\section{DISCUSSION}

It has been well-documented that alginate-based raftforming formulations help to achieve symptomatic relief from GERD, and variations in the amounts of sodium alginate and antacids, and the type of antacid used can have a profound effect on raft-formation and its performance in vivo. ${ }^{1,6,8,26}$

The in vitro studies described in the present investigation focussed on the physicochemical characterization of rafts and estimation of the alginate content in raft-forming formulations. The study also assessed raft strength and resilience and explained how the alginate and antacid contents of the formulations could influence product performance in terms of raft structure, raft integrity and neutralization profiles. The six products evaluated in this study were ones commercially available in the Indian market. These products contained sodium alginate as the main ingredient along with antacids, amount of alginate per maximum dose being variable. Further, the antacid composition and the proportion of alginate to antacid were different for all products.

Higher alginate content resulted in higher entrapment of antacids within the raft matrices and hence better acid neutralization properties. The carbonate content of the antacids reacted with the gastric acid to generate carbon dioxide, which got trapped within the rafts and imparted buoyancy to them. Digeraft ${ }^{\mathrm{TM}}$ and $\mathrm{RG}$, due to their higher carbonate content, resulted in more buoyant and highly porous rafts compared with those of other four products.

Only two products, Digeraft ${ }^{\mathrm{TM}}$ and RG complied with the BP specifications for alginate content and raft strength. The higher strength, coherence and resilience of rafts of Digeraft $^{\mathrm{TM}}$ and $\mathrm{RG}$ can be attributed to the insoluble calcium alginate matrix formed due to interaction of alginate with calcium ions in the co-formulated antacid in these products as has been observed previously for other raft-forming products containing calcium-based antacids. ${ }^{14,18,26}$ Another possible explanation was the higher alginate content per dose in these products, 10 times higher than that of RR and RM and 5 times higher than that of RV and RT. Formulations with higher alginate content formed a concentrated alginate gel that reacts with calcium ions to form stronger and coherent rafts. ${ }^{6,12,18}$ The presence of aluminium and magnesium ions in the other four products resulted in weaker rafts, although alginate content per dose for these were high; hence they failed the BP specification for raft strength. ${ }^{18,27,28}$

The structural and thermal characterization of the rafts confirmed the presence of alginate biopolymer and also accounted for its interaction with the antacid components in the various formulations.

Majority of the in vitro studies previously reported for raft-forming formulations have mainly focussed on physical assessments such as raft strength and resilience as a means to compare their in vivo performances. ${ }^{14,18}$ Recently, Dettmar et al reported chemical characterization of raft-forming formulations available in the global market and emphasized on alginate content as the key influencer of product performance in terms of 
neutralization properties. ${ }^{6}$ This study focused on extensive physical as well as chemical characterization of raftforming products in the Indian market and provided insights into the influence of formulation parameters on the raft properties and potential impact on product performance in vivo. However, further evaluation of the products in GERD patients is essential for understanding the real-time product performances under the gastrointestinal peristalsis and acid secretion cycles.

\section{CONCLUSION}

Considerable differences were found in the acid neutralization properties, strength and resilience of the rafts of the alginate-based products available in the Indian market. These differences can be attributed to alginate and antacid contents and antacid types. These results indicate that interaction of alginate with antacids in the raftforming products can significantly influence the formation and physicochemical properties of the rafts and consequently, the in vivo clinical efficacy of the products in relieving GERD symptoms. Further studies with varying doses and alginate content and in vivo clinical studies are necessary to corroborate these findings.

\section{ACKNOWLEDGEMENTS}

The authors wish to acknowledge the support of Sagar Pednekar and Mahima Nevrekar (students of Bombay College of Pharmacy) in the preliminary screening and acid neutralization experiment and Dr. M. K. Rangnekar laboratories for the facility of infrared spectroscopy.

Funding: This study was funded by Abbott India Ltd. Conflict of interest: Chandrashekhar Gargote, Nischal Shashidhar and Sneha Nair are employees of Abbott Ethical approval: Not required

\section{REFERENCES}

1. Rohof WO, Bennink RJ, Smout AJ, Thomas E, Boeckxstaens GE. An alginate-antacid formulation localizes to the acid pocket to reduce acid reflux in patients with gastroesophageal reflux disease. J Clinic Gastroenterol Hepatol. 2013;11(12):1585-91.

2. Boeckxstaens G. The relationship between the acid pocket and GERD. Gastroenterol Hepatol. 2013;9(9):595.

3. Antunes C, Aleem A, Curtis SA. Gastroesophageal Reflux Disease. Treasure Island (FL): StatPearls Publishing; 2021.

4. Eusebi LH, Ratnakumaran R, Yuan Y, SolaymaniDodaran M, Bazzoli F, Ford AC. Global prevalence of, and risk factors for, gastro-oesophageal reflux symptoms: a meta-analysis. Gut. 2018;67(3):430-40.

5. Bhatia SJ, Makharia GK, Abraham P, Bhat N, Kumar $\mathrm{A}$, Reddy DN, et al. Indian consensus on gastroesophageal reflux disease in adults: a position statement of the Indian Society of Gastroenterology. Indian J Gastroenterol. 2019;38(5):411-40.
6. Dettmar PW, Gil-Gonzalez D, Fisher J, Flint L, Rainforth D, Moreno-Herrera A, et al. A comparative study on the raft chemical properties of various alginate antacid raft-forming products. Drug Develop Industr Pharma. 2018;44(1):30-9.

7. Lopes CM, Bettencourt C, Rossi A, Buttini F, Barata $\mathrm{P}$. Overview on gastroretentive drug delivery systems for improving drug bioavailability. Int $\mathbf{J}$ Pharmaceut. 2016;510(1):144-58.

8. Prajapati VD, Jani GK, Khutliwala TA, Zala BS. Raft forming system-an upcoming approach of gastroretentive drug delivery system. J Controlled Release. 2013;168(2):151-65.

9. Ramdas T, Hosmani A, Somwanshi S. Raft technology for gastro retentive drug delivery. Int $\mathbf{J}$ Pharm Pharmaceut Res. 2015;3:232-52.

10. Daggy M, Brodie J, Jacoby H. Review article: alginate-raft formulations in the treatment of heartburn and acid reflux. Aliment Pharmacol Therapeut. 2000;14(6):669-90.

11. Yousaf M, Nirwan JS, Smith AM, Timmins $P$, Conway BR, Ghori MU. Raft-forming polysaccharides for the treatment of gastroesophageal reflux disease (GORD): systematic review. J Appl Polymer Sci. 2019;136(40):48012.

12. Enobakhare B, Bader D, Lee D. Concentration and $\mathrm{M} / \mathrm{G}$ ratio influence the physiochemical and mechanical properties of alginate constructs for tissue engineering. J Appl Biomaterial Biomech. 2006;4(2):87-96.

13. Kapadia CJ, Mane VB. Raft-forming agents: antireflux formulations. Drug Development Industrial Pharm. 2007;33(12):1350-61.

14. Hampson F, Farndale A, Strugala V, Sykes J, Jolliffe I, Dettmar P. Alginate rafts and their characterisation. Int J Pharmaceut. 2005;294(1-2):137-47.

15. Washington $\mathrm{N}$, Washington $\mathrm{C}$, Wilson $\mathrm{C}$, Davis $\mathrm{S}$. The effect of inclusion of aluminium hydroxide in alginate-containing raft-forming antacids. Int $\mathbf{J}$ Pharmaceut. 1986;28(2-3):139-43.

16. Monograph-compound alginate antacid oral suspension, in British Pharmacopoeia. London, UK: The Stationary Office.

17. Darwish MK, El-Enin AS, Mohammed KH. Formulation, optimization, and evaluation of raftforming formulations containing Nizatidine. Drug Development Industr Pharm. 2019;45(4):651-63.

18. Hampson FC, Jolliffe IG, Bakhtyari A, Taylor G, Sykes J, Johnstone LM, et al. Alginate-antacid combinations: raft formation and gastric retention studies. Drug Development Industr Pharm. 2010;36(5):614-23.

19. Poddar U. Diagnosis and management of gastroesophageal reflux disease (GERD): an Indian perspective. Indian Pediatrics. 2013;50(1):119-26.

20. Hanif M, Shah S, Rasul GA, Zaman M, Amjad MW, Raja MAG, et al. Enhancement of oral bioavailability of ibandronate through gastroretentive raft forming drug delivery system: in vitro and in vivo evaluation. Int J Nanomed. 2020;15:4847-58. 
21. Gupta A, Garg S, Khar RK. Measurement of bioadhesive strength of mucoadhesive buccal tablets: design of an in-vitro assembly. Indian Drug Bombay. 1993;30:152.

22. Prajapati ST, Mehta AP, Modhia IP, Patel CN. Formulation and optimisation of raft-forming chewable tablets containing $\mathrm{H} 2$ antagonist. Int $\mathrm{J}$ Pharmaceut Investigat. 2012;2(4):176.

23. Hampson F, Banks A, Jolliffe I, Dettmar P. Raft resilience in alginate anti-reflux products. J Pharm Pharmacol. 2002;54:30-1.

24. Awad H, Aboul-Enein HY. A validated HPLC assay method for the determination of sodium alginate in pharmaceutical formulations. J Chromatogra Sci. 2013;51(3):208-14.

25. Skoog DA, Holler FJ, Crouch SR. Infrared absorption spectroscopy. principles of instrumental analysis. 7th ed. Cengage learning; 2017.

26. Strugala V, Dettmar PW, Thomas E. Evaluation of an innovative over-the-counter treatment for symptoms of reflux disease: quick-dissolving alginate granules. Int Scholar Res Notice. 2012;2012:1-7.

27. Washington N, Wilson C, Davis S. Evaluation of 'raft-forming'antacid neutralizing capacity: in vitro and in vivo correlations. Int $\mathbf{J}$ Pharmaceut. 1985;27(2-3):279-86.

28. Wilkinson J, Abd-Elaziz K, denDaas I, Wemer J, vanHaastert M, Hodgkinson V, et al. Two placebocontrolled crossover studies in healthy subjects to evaluate gastric acid neutralization by an alginateantacid formulation (Gaviscon double action). Drug Development Industr Pharm. 2019;45(3):430-8.

Cite this article as: Savla HM, Naik IV, Gargote C, Shashidhar N, Nair S, Menon MD. Physicochemical properties of various alginate-based raft-forming antacid products: a comparative study. Int J Basic Clin Pharmacol 2021;10:1330-41. 